ACCEPTED MANUSCRIPT

\title{
Special Issue on Multiprobe Techniques
}

To cite this article before publication: Christoph Tegenkamp et al $2018 \mathrm{~J}$. Phys.: Condens. Matter in press https://doi.org/10.1088/1361$\underline{648 \mathrm{X} / \mathrm{aaee} 03}$

\section{Manuscript version: Accepted Manuscript}

Accepted Manuscript is "the version of the article accepted for publication including all changes made as a result of the peer review process, and which may also include the addition to the article by IOP Publishing of a header, an article ID, a cover sheet and/or an 'Accepted Manuscript' watermark, but excluding any other editing, typesetting or other changes made by IOP Publishing and/or its licensors"

This Accepted Manuscript is ( 2018 IOP Publishing Ltd.

During the embargo period (the 12 month period from the publication of the Version of Record of this article), the Accepted Manuscript is fully protected by copyright and cannot be reused or reposted elsewhere.

As the Version of Record of this article is going to be / has been published on a subscription basis, this Accepted Manuscript is available for reuse under a CC BY-NC-ND 3.0 licence after the 12 month embargo period.

After the embargo period, everyone is permitted to use copy and redistribute this article for non-commercial purposes only, provided that they adhere to all the terms of the licence https://creativecommons.org/licences/by-nc-nd/3.0

Although reasonable endeavours have been taken to obtain all necessary permissions from third parties to include their copyrighted content within this article, their full citation and copyright line may not be present in this Accepted Manuscript version. Before using any content from this article, please refer to the Version of Record on IOPscience once published for full citation and copyright details, as permissions will likely be required. All third party content is fully copyright protected, unless specifically stated otherwise in the figure caption in the Version of Record.

View the article online for updates and enhancements. 
The multiprobe technique based on scanning tunneling microcopy (STM) has become very popular over the past few years and has demonstrated its capability to reveal fundamental nanoscale charge transport properties Compared to conventional, i.e. lithographicallydriven concepts, the four-tip STM technique can directly contact delicate nanostructures with upmost precision. Moreover, the reliable and individual positioning of the STM-tips allows the assembly and manipulation of such complex nanostructures. Together with the STM, STS, and potentiometry capabilities, an almost complete set of information with respect to the atomic structure, electronic states, and conductivity (even spin-polarized) can be gathered in-situ from

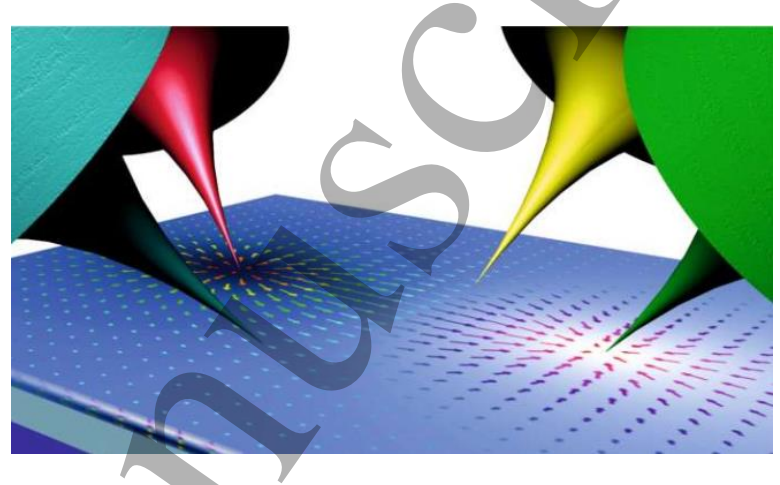

Figure 1: Artist view of a multiprobe system with 4 scanning tunneling tips approached to a surface. This image, "Scheme of a multi-tip STM", was created by the authors and originally used on the Wikipedia article "Multitip scanning tunneling microscopy" where it was made available under a CC BY-SA 4.0 licence. It is included within this article on that basis. It is attributed to Bert Voigtländer. emergent nanomaterials without the need for elaborate transfers.

The invention of multiprobe STM is a result of a consistent further development of various multiprobe approaches used in the field of surface science. In the beginning, electric contacts with fixed geometries, realized by shadow masks or simply by clamps, were used in order to correlate surface conductivity with its morphology $[1,2,3]$. In the course of an increasing interest into precise surface conductance measurements, the first multiprobe systems were developed. In order to simplify the ex-situ sample preparation and to access now also the mesoscopic length scale, monolithic chip designs hosting various contact assemblies became available [4,5]. During this time, the first generation of multiprobe STM systems were developed, where all contacts could be navigated independently $[6,7]$.

This special issue is a collection of papers, which maps the current research and application of multiprobe STM systems. For instance, two-probe transport experiments on a single $156 \mathrm{Ge}$ dimer wire on $\mathrm{H}: \mathrm{Ge}(100)$ demonstrate the truly atomic scale capability, which can be reached nowadays [8]. A major advantage compared to conventional transport experiments is that variable contact spacings and geometries can be easily realized in-situ. This mode is particular appealing for low dimensional electron gas systems like wires or films, as one has a direct access to the homogeneity and anisotropy, as greatly explored for atomic steps and grain boundaries in epitaxially grown $\mathrm{Bi}_{2} \mathrm{Se}_{3}$ films [9]. The insitu capability allows the combination of high-resolution transport with complementary surface science techniques, e.g. XPS, as confirmed by the optimization of $\mathrm{ZnO}$ surfaces by light plasma treatments [10]. Moreover, the stability of state-of-the-art multiprobe instrumentations is impressive and allow to realize even measurements at freestanding nanowires. This was demonstrated for functionalized GaAs-nanowires grown by self-assembly on surfaces [11]. One strength of this technique is the probe-spacing dependent transport measurement, which gives a direct access to the dimensionality and environmental coupling of the system. In order to relate the measured resistance 
with the resistivity of the system, highly symmetric tip geometries, e.g. equidistant and collinear assembly, are often used. Albeit theoretically more complex, a simplified 4-probe method was developed now in which only one tip needs to be navigated [12]. Besides such aspects, also applicationdriven research was performed. For instance, the connectivity of carbon nanofiber mats, which are used for lightweight construction, was analyzed by nanoscale transport [13]. Recently, the multiprobe technique was used for manipulation, i.e. contacting metallic wires in order to study failure processes in nanostructures and to use this technique to fabricate ultra-small junctions for single molecules [14].

The continuous and still ongoing improvement of this technique over the last years by many groups made it a reliable technique for surface science and nanotechnology. This includes also the development of new modes of operations, e.g., in order to simplify the setup or to be truly noninvasive. For instance, the surface potentials can be measured with a potentiometric manner within the tunneling contact, thus resistivities can be measured without being in contact to the sample [15].

We hope that the reader enjoys this special issue. We thank all contributors to this special issue and look forward to more experiments in order to elucidate the entire potential of this powerful technique.

\section{Acknowledgements}

The image in this publication was created by the authors and originally used on the Wikipedia website, where it were made available under a Creative Commons licence. Please see figure caption in this publication for details. To the extent that the law allows, IOP Publishing disclaim any liability that any person may suffer as a result of accessing, using or forwarding the image. Any reuse rights should be checked and permission should be sought if necessary from Wikipedia and/or the copyright owner (as appropriate) before using or forwarding the image."

References:

[1] R. Schad, S. Heun, T. Heidenblut, M. Henzler, Appl. Phys. A 55, 231 (1992).

[2] S. Hasegawa, S. Ino, Phys. Rev. Lett. 68, 1192 (1992).

[3] T. Uchihashi, U. Ramsperger, Apl. Phys. Lett. 80, 4169 (2002).

[4] P. Bøggild, F. Grey, T. Hassenkam, D.R. Greve, T. Bjørnholm, Adv. Materials, 12, 947 (2000).

[5] L. Gammelgaard, et al., Appl. Phys. Lett. 93, 093104 (2008).

[6] M. Aono, T. Nakayama et al., OYO Buturi 67, 1361 (1998).

[7] I. Shiraki, F. Tanabe, R. Hobara, T. Nagao, S. Hasegawa, Surf. Sci. 493, 633 (2001).

[8] M. Kolmer, P. Olszowski, R. Zusak, S. Godleski, C. Joachim, M. Szymonski, JPCM 29, 444004 (2017).

[9] S. Bauer and C.A. Bobisch, JPCM 29, 334002 (2017).

[10] A.M. Lord, J.E. Evans, C.J, Barnett, M.W. Allen, A.R. Barron, S.P. Wilks, JPCM 29, 384001 (2017).

[11] A. Nägelein, L. Liborius, M. Seidl, C. Blumberg, P. Kleinschmidt, A. Poloczek, T. Hannappel, JPCM

29, 394007 (2017).

[12] S.B. Kjeldby, O.E. Evenstad, S.P. Coois, J.W. Wells, JPCM 29, 394008 (2017).

[13] J. Aprojanz, B. Dreyer, M. Wehr, J. Wiegand, J. Baringhaus, J. Koch, F. Renz, R. Sindelar, C.

Tegenkamp, JPCM 29, 494002 (2017).

[14] A, Chatterjee, T. Bai, F. Edler, C. Tegenkamp, K. Weide-Zaage, H. Pfnür, JPCM 30, 084002 (2018).

[15] F. Lüpke, D. Cuma, S. Korte, V. Cherepanov, B. Voigtländer, JPCM 30, 054004 (2018). 